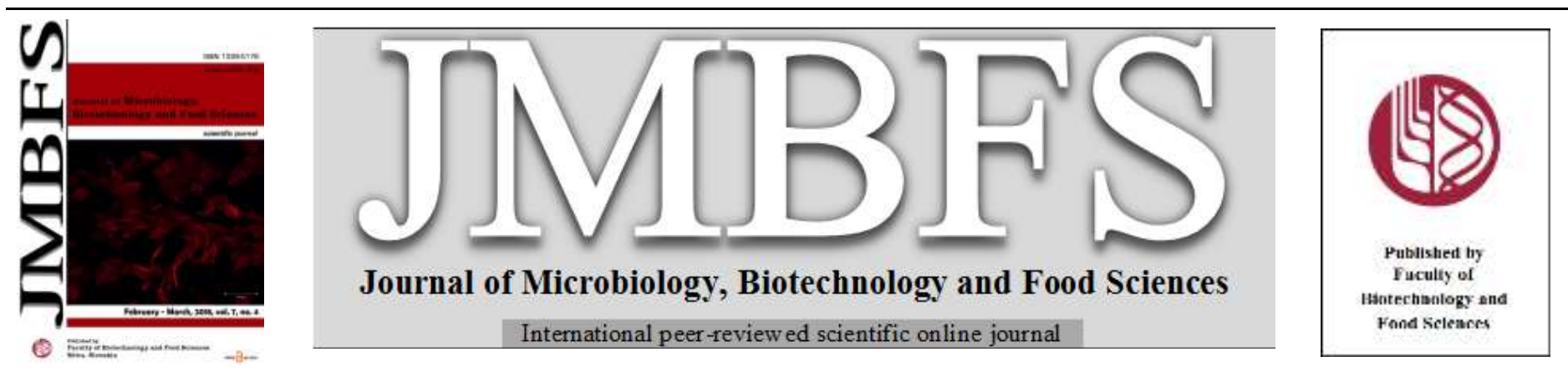

\title{
ANTIDERMATOPHYTIC ACTIVITY OF GREEN SYNTHESISED ZINC OXIDE NANOPARTICLES USING Cassia alata LEAVES
}

\author{
J. Sujatha* ${ }^{1}$, S. Asokan ${ }^{2}$ and S. Rajeshkumar ${ }^{3}$ \\ Address(es): \\ ${ }^{1} \mathrm{PG}$ and Research Department of Microbiology, Marudupandiyar College, Vallam, Thanjavur, TN, India - 613403. \\ ${ }^{2}$ Department of Microbiology, Annai college of Arts and Science, Kovilacheri, Kumbakonam-612 503. \\ ${ }^{3}$ School of Bio-sciences and Technology, VIT University, Vellore - 632014, TN, India. \\ *Corresponding author: jsujatha107@gmail.com
}

doi: 10.15414/jmbfs.2018.7.4.348-352

ARTICLE INFO

Received 3.11. 2017

Revised 18. 11. 2017

Accepted 22. 11. 2017

Published 1. 2. 2018

Regular article

orte access

\begin{abstract}
The green techniques are plying a major role in the synthesis of nanoparticles and in this present study we used the herbal plant Cassia alata for the green synthesis of zinc oxide nanoparticles. This reducing agent generates zinc oxide nanoparticles (ZnO NPs) from zinc acetate solution within 15 minutes. The synthesized ZnO NPs was characterized by UV-vis spectrophotometer shows surface Plasmon resonance band at $335 \mathrm{~nm}$. Scanning electron microscope (SEM) image showed the size of the crystalline nanoparticles ranging from 30- $50 \mathrm{~nm}$. Energy dispersive X-ray analysis (EDAX) confirms the presence of elemental $\mathrm{Zn}$ and $\mathrm{O}$ in the synthesized nanoparticles. FTIR revealed that presence of functional molecules like carboxylic acids, amine ant nitro groups associated with synthesized oxide nanoparticles. Atomic force microscope (AFM) shows spherical shape of nanoparticles as well as aggregation also observed. Thus green synthesized nanoparticles were tested for their antidermatophytic potential against Trichophyton mentagrophyte, Trichophyton rubrum, Epidermophyton floccosum, Microsporum audouinii, and Microsporum canis and recorded percentage of inhibition, MIC and
\end{abstract} MFC values.

Keywords: Zinc oxide nanoparticles, green synthesis, Cassia alata, Antidermatophytic activity

\section{INTRODUCTION}

Dermatophytosis is common skin disease and also known as ringworm caused by fungal species mainly keratin digesting fungi. The mode of transmission of ringworm disease is skin to skin contact. The genera of dermatophytes are Microsporum, Trichophyton and Epidermophyton (White et al., 2008 Peres et al., 2010). Dermatophytes are evolved from soil residing keratinophilic organisms (Chuang et al., 2007). Dermatophytes cause infection mainly in hair, nails and skin and this disease can be mild or severe based on immune response of host cells (Abdel-Rahman, 2001; Macedo et al., 2005). Dermatophytes have the ability to produce proteolytic enzymes which are involved in hydrolyze of keratin (Akcaglar et al., 2011). Antifungal agents were used to heal the skin infection. After the skin healed, the treatment for ringworm is continued for 1-2 weeks. Common antifungals include Clotrimazole, Econazole, Ketoconazole, Miconazole, and Terbinafine. Terbinafine is a cream which applied in daily and it found to be an alternative. Usually it requires maximum one week to cure the disease compared to other antifungal agent but this remedy is expensive (Soares et al 2013).

Nanomaterials are the nanometre sized falls with ranges from 1-100 nm and these materials showed enhanced unique properties (Charinpanitkul et al 2008) Various types of nanoparticles are manipulated by physical, chemical and bio method. The nanoparticles are highly used as a antimicrobil agents like antibacterial and antifungal activities against different types of disease causing pathoens (Soumya et al 2017, Venkat Kumar and Rajeshkumar 2017, Sujatha et al 2017, Rajeshkumar and Bharath 2017, Santhoshkumar et al 2017, Rajeshkumar 2016). Among other types of nanoparticles, metal oxide nanoparticles were having high antimicrobial activity due their increased surface area to volume ratio (Das Purkayastha and Manhar 2016). Zinc oxide nanoparticles are classified under metal oxide nanoparticles which is an n-type semiconducting metal oxide. ZnO NPs are much interested in research due to its wide range of applications in various fields of system and also they are inexpensive to fabricate, safe, simple and eco-friendly (Abdul et al 2014; Agarwal et al 2017). Due to the presence large band gap, $\mathrm{ZnO}$ nanoparticles exhibit catalytic activity, optic, antiinflammatory, and wound healing activity
(Mirzaei and Darrroudi 2017; Stan et al 2015). Moreover, ZnO NPs was mostly used in sunscreen lotions due to its UV filtering properties.

Various methods are currently used in $\mathrm{ZnO}$ nanoparticles like sol gel, laser ablation, solvothermal, thermolysis, and chemical vapour deposition techniques. The physical and chemical methods of production of nanoparticles are usually expensive and toxic to the environment and living systems. But the biological method offers simple and cost effective route of synthesis of nanoparticles. Moreover, green method of nanoparticles production offers, compatible, elimination of culture maintaining process, less time consuming and ecofriendliness. Currently, plant extract mediated synthesis method was achieved using different parts like bark, stem, root (Anand Raj and Jayalakshmy 2015), leaf (Sangeetha et al 2011; Elumalai and Velmurugan 2015), flower, fruit, peel (Mishra and Sharma 2015) and seed. The parts of plant has photochemical constituents like glucosides, apin, arthocyanins and quercetin which are act as reducing agents as well as involved in the stabilization of nanoparticles (Yedurkar et al 2016).

C. alata $\mathrm{L}$ is the member of Fabaceae family and can be grow $\mathrm{n}$ diverse habits. $\mathrm{C}$. alata is an erect and herb which grows up to about $8 \mathrm{~m}$ tall with leathery compounded leaves. Traditionally, the species of Cassia exhibits antimicrobial property (Somchit et al., 2003) and it is used to treat ringworm and skin diseases in Thailand (Farnsworth and Bunyaprapatsara, 1992). The extract of leaves is considered as a good antioxidant agent, medicine for parasitic skin diseases, and is used in much eruptive and pustular skin (Phongpaichit et al 2004). In this study C. alata leaves extract was used to synthesis of $\mathrm{ZnO}$ nanoparticles and assessment of antidermatophytic activity against fungal species.

\section{MATERIAL AND METHODS}

\section{Collection of plant}

The plant Cassia alata was collected from Vandhavasi, Tamilnadu. Photo of this plant was taken from Vandhavasi

Preparation of plant leaf extract 
About $20 \mathrm{~g}$ of $C$. alata leaves was finely chopped and washed with tap water followed by double distilled water. Leaves were boiled with $100 \mathrm{ml}$ of distilled water in a beaker. After boiling extract was filtered using Whatman No 1 filter paper and collect the filtrate which is used to nanoparticles synthesis.

\section{Green Synthesis of ZnO Nano`particles}

In the typical synthesis of $\mathrm{ZnO}$ nanoparticles, $10 \mathrm{ml}$ of plant extract was added into $90 \mathrm{ml}$ of $1 \mathrm{mM}$ Zinc acetate solution and kept it in stirring for constant mixing under room temperature. A color change of the solution was noted by visual examination confirming the synthesis of Zinc oxide nanoparticles.

\section{Purification and Characterization of synthesized Zinc oxide nanoparticles}

Colour change of bioreduction of Zinc oxide ions in aqueous solution was monitored by Double beam UV-vis spectrophotometer at different wavelength region from 320-700 $\mathrm{nm}$. The bioreduced Zinc oxide ions were purified for further characterization studies by subjected to centrifugation at $10,000 \mathrm{rpm}$ for 15 min. The purified Zinc oxide nanoparticle was morphologically characterized by using the Scanning Electron Microscope. Elemental analysis and crystalline structure of nanoparticles was examined by EDAX, respectively. Functional groups involved in the synthesis of zinc oxide nanoparticles were identified by FTIR spectrum. The study of morphological characters based on topography analysis was conducted by Atomic Force Microscope.

Anti-dermatophytic activity of $\mathrm{ZnO}$ nanoparticles synthesized by using $C$. alata leaves

\section{Collection of dermatophytes}

Dermatophytes like Trichophyton mentagrophytes (MTCC-7687), Trichophyton rubrum (MTCC-7859), Epidermophyton floccosum (MTCC-7880), Microsporum audouinii (MTCC- 8197), and Microsporum canis (MTCC- 3270) were purchased from MTCC, Chandigarh.

\section{Antifungal activity by Agar well diffusion method}

Antifungal activity of synthesized $\mathrm{ZnO}$ nanoparticles was assessed by the measuring of zone of inhibition of fungal growth around the well. Sterilized Potato dextrose medium was prepared and poured into petriplates. These sterile petriplates were allowed to solidify and swab the detmatophytes fungal spores using sterile cotton swab in each petriplates. In the culture inoculated plates, four wells were made with the diameter of $5 \mathrm{~mm}$ using gel puncture. Differen concentrations of $\mathrm{ZnO}$ NPs $(25,50$, and $75 \mu \mathrm{l})$ were filled in each well and plates were incubated at $37^{\circ} \mathrm{C}$ for $24-48 \mathrm{~h}$. After incubation, the different levels of zone of inhibition were measured around the well. The statistical analysis of standard error was calculated using triplicates of experiments $(n=3)$. From this percentage of inhibition of nanoparticles was calculated by subtracting from control. Positive control is considered as $100 \%$ inhibition was compared with nanoparticles.

\section{Determination of minimum inhibitory concentration}

The MIC of the synthesized zinc oxide nanoparticles was determined at different concentrations are $25-75 \mu \mathrm{l} / \mathrm{ml}$. In $250 \mathrm{ml}$ conical flasks the media Saboroud dextrose broth was prepared and sterilized in autoclave. After sterilization different concentration of $\mathrm{ZnO}$ nanoparticles were added separately in each flask. To this, $0.1 \mathrm{ml}$ of fungal inoculums spores $\left(1 \times 10^{7} \mathrm{cfu} / \mathrm{ml}\right)$ was added in each flask and the flasks were incubated at $37^{\circ} \mathrm{C}$ for 24 to $48 \mathrm{hrs}$. The positive (antibiotic mixed) and negative (without $\mathrm{ZnO}$ nanoparticles) control was maintained. Minimum inhibition concentration was determined by observing turbidity. There is no turbidity or fungal growth was observed in broth is noted as minimum inhibitory concentration.

\section{Determination of Minimum Fungicidal concentration}

The in vitro minimum fungicidal activity (MFC) was determined described by Espinel-Ingroff et al. (2002). Different concentration of nanoparticles was mixed with fungal culture inoculated flaks were made subculture from each flasks and spread on PDA containing plates. Plates were incubated for $72 \mathrm{~h}$ at room temperature. After incubation, all the plates were observed that showed no visible growth is a $100 \%$ of inhibition. Lowest concentration that required inhibiting the growth of dermatophytes fungal species is considered as minimum fungicidal concentration (MFC).

\section{RESULTS AND DISCUSSION}

In the nanoparticles synthesis experiment, $C$. alata leaves extract was added into the $1 \mathrm{mM}$ of Zinc acetate solution leads to the change in the color of the reaction solution. The leaf extracts of $C$. alata changed in to yellowish white precipitate when challenged with $1 \mathrm{mM}$ Zinc acetate solution (Figure 1 (A) \& (B)). C. alata leaf extract has been used for the reducing material as well as surface stabilizing agent for the synthesis of spherical shaped $\mathrm{ZnO}$-NPs. Color change from white to pale yellow represents the synthesis of $\mathrm{ZnO}$ NPs.

\section{(A)}

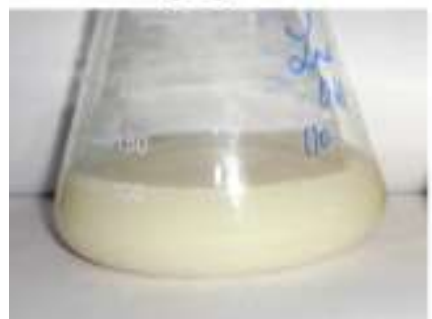

(B)

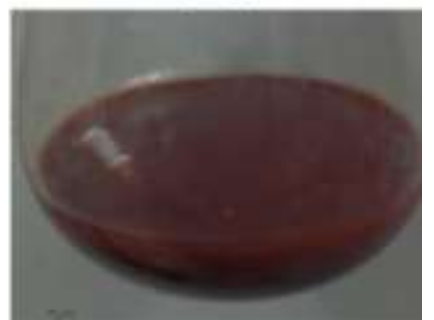

Figure 1 Visual observation of ZnO NPs synthesis C.alata leaves extract (A) yellowish white colour at initial (B) final color change

\section{UV-vis spectroscopy}

The optical absorption spectra of green synthesized zinc oxide nanoparticles were recorded using UV - vis Spectrophotometer at different wavelength is in the range of 300 to $500 \mathrm{~nm}$. Figure 2 shows the UV-vis absorption spectrum of zinc oxide nanoparticles. The spectrum showed the absorbance peaks at $335 \mathrm{~nm}$ which is corresponding to the characteristic band of zinc oxide nanoparticles (Imitan et al., 2009) synthesized by leaf extract of $C$. alata respectively.

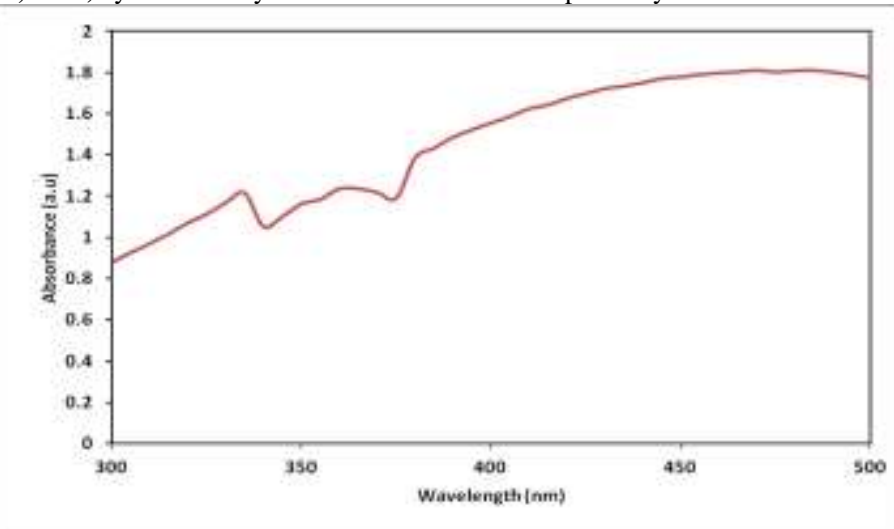

Figure 2 UV-vis spectrum of $\mathrm{ZnO}$ NPs synthesized by leaf extract of $C$. alata

\section{Scanning Electron Microscope}

The surface morphology and size of the zinc oxide nanoparticles was identified by Scanning Electron Microscope. SEM image had shown shape and size of the zinc oxide nanoparticles synthesized by using leaf extract of $C$. alata Figure 3(a) and (b) shows the surface morphology of the zinc oxide nanoparticles synthesized by using leaf extract of $C$. alata recorded under different magnifications. It shows mostly rod shaped $\mathrm{ZnO}$ nanoparticles as well as number of aggregates synthesized using leaf extract of $C$. alata. The SEM image showed that most of the nanoparticles are rod in shape formed within diameter range of 30 - $50 \mathrm{~nm}$. Yedurkar et al (2016) synthesized $\mathrm{ZnO}$ nanoparticles are spherical in shape formed within diameter range of 80 - $130 \mathrm{~nm}$ using Ixora coccinea leaf extract.
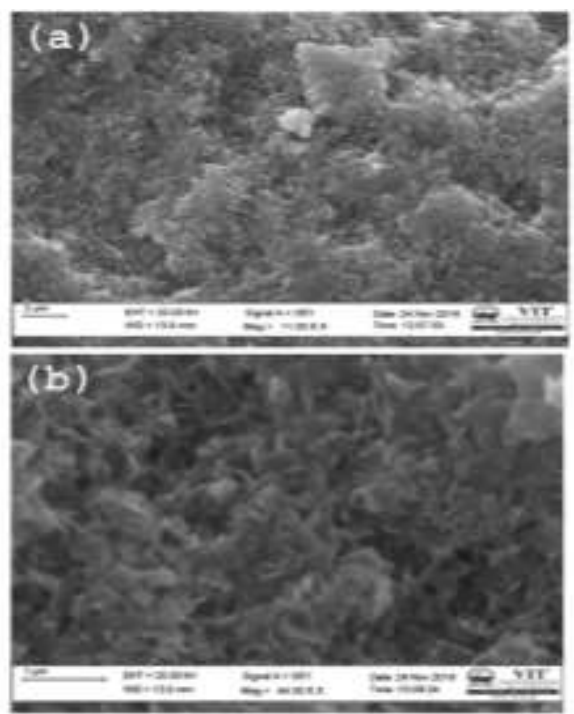
Figure 3 SEM image of $\mathrm{ZnO}$ NPs synthesized from $C$. alata leaf extract at different scale bar (a) $2 \mu \mathrm{m}$ (b) $1 \mu \mathrm{m}$

EDX

EDAX spectrum (Figure 4) revealed that the other elements along with Zinc are identified in the synthesized $\mathrm{ZnO}$ nanoparticles. Figure shows the EDAX analysis, confirmed the presence of metallic zinc oxide in biosynthesized $\mathrm{ZnO}$ NPs. The composition obtained from EDAX analysis was Zinc and Oxygen at the Plasmon resonance peak of $8.5 \mathrm{eV}$ and $1 \mathrm{eV}$, respectively. Additionally, Calcium and carbon was observed in $C$. alata leaf extract mediated synthesized $\mathrm{ZnO}$ nanoparticles. The presence of carbon and calcium in trace amount indicates the involvement of plant phytochemical groups in reduction and capping of the synthesized ZnO nanoparticles (Raut et al 2013).

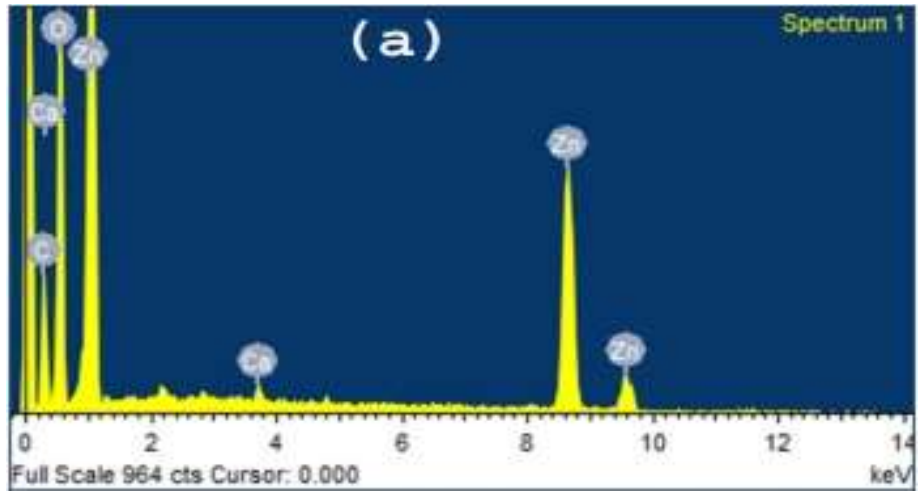

Figure 4 EDX Spectrum of $\mathrm{ZnO}$ nanoparticles synthesized from C. alata

\section{FT-IR analysis}

FT-IR spectra used to identify the functional group of C.alata leaf extract involved in ZnO NP synthesis illustrated peak in the range of $450-4000 \mathrm{~cm}^{-1}$ (Figure 5). Broad peak obtained at 3282.31 corresponded to $\mathrm{OH}$ stretching vibrations of carboxylic acids, peak in the range of $1409.74 \mathrm{~cm}^{-1}$ corresponded to CC stretch in aromatic ring. Weak peaks obtained at and $1017.85 \mathrm{~cm}^{-1}$ and $643.62 \mathrm{~cm}^{-1}$ demonstrated the presence of and C-O stretch in alcohols and C-Br stretch alkyl Halide (Table 1). Similarly, some researchers resulted that alcohol, aliphatic amine, phenols and carboxylic acids are the functional groups associated with nanoparticles (Rastogi and Arunachalam, 2011; Das et al., 2011; Awwad et al., 2013; Jamdagni et al 2016).

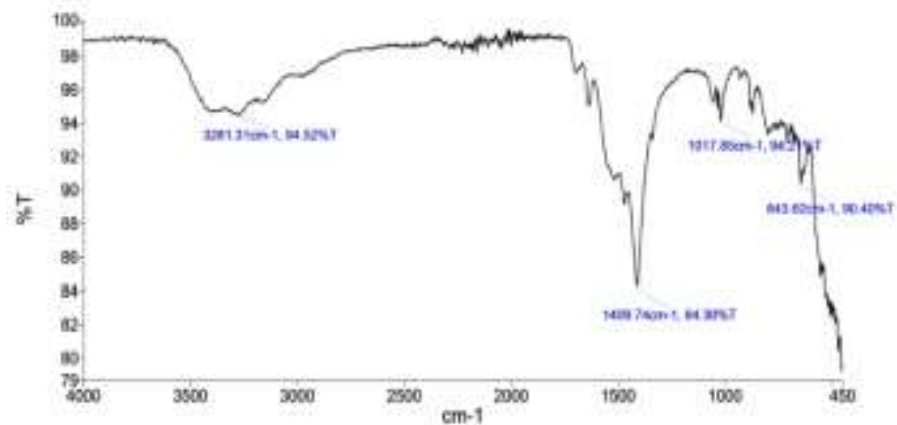

Figure 5 FT-IR Spectrum of ZnO NPs with plant leaf extract of $C$. alata

\section{AFM analysis}

AFM analysis is gives us insight about the topography, roughness of nanoparticles. AFM imaging was conducted in different magnification ranges of 5 and $25 \mu \mathrm{m}$. AFM (Figure 6(a) and (b)) image clearly demonstrate smooth nanoparticle with capping of phytochemicals over the surface of nanoparticles which are synthesized by leaf extract of $C$. alata (Femi et al 2011).
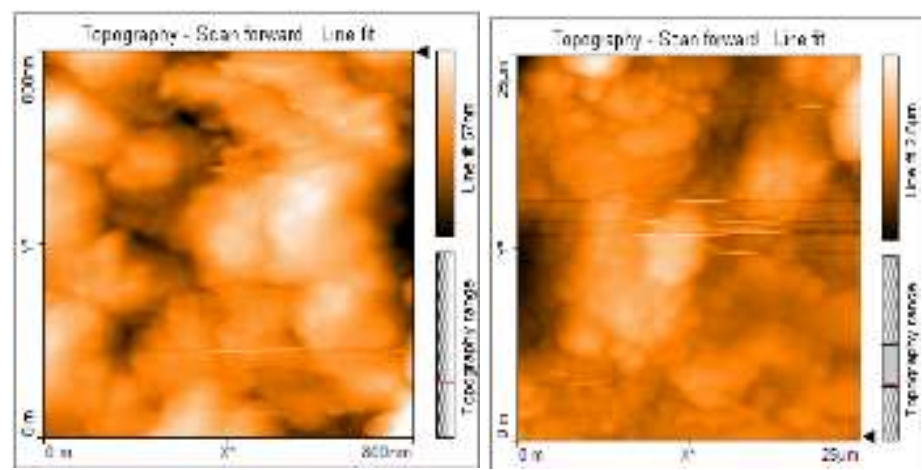

Figure 6 AFM images of $C$. alata mediated synthesis of $\mathrm{ZnO}$ nanoparticles Antidermatophytic activity of $\mathrm{ZnO}$ NPs synthesized by using $C$. alata leaf extract

The results of antifungal sensitivity of $\mathrm{ZnO}$ nanoparticles synthesized by using extract of $C$. alata leaves against the five different dermatophytic fungal strains are interpreted in table 1-3 and Figure 7.

Results clearly demonstrate that the nanoparticles showed anti- bacterial effect in a dose-dependent manner (Figure 7 and Table 1). Maximum zone of inhibition was observed against the dermatophytes T. rubrum. Minimum zone of inhibition was observed against $M$. canis. Zone of inhibition obtained using nanoparticles was much lower than the standard disc used which depicts the need of further engineering of nanoparticles to obtain desirable effects. The entire tests were done in triplicate. The zinc oxide nanoparticles are inhibits the microbial growth in in-vitro antimicrobial activities.

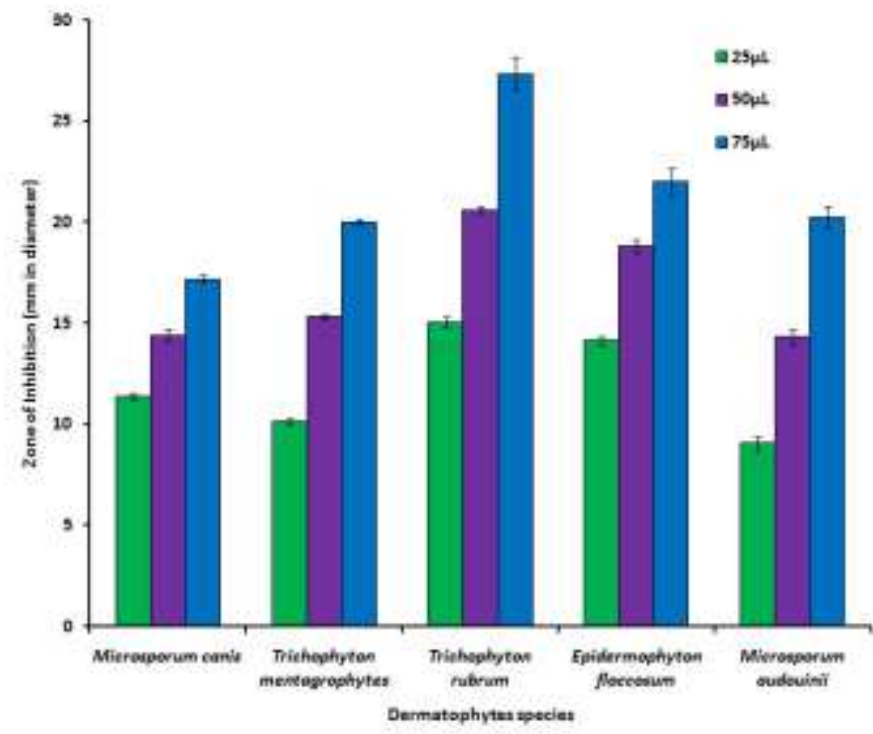

Figure 7 Anti-dermatophytic activity of $\mathrm{ZnO}$ NPs synthesized using the extract of $C$. alata leaves against dermatophytes at different concentrations

Table 1 Zone of inhibition of ZnO NPs synthesized using the extract of $C$. alata leaves against dermatophytes

\begin{tabular}{lccc}
\hline \multirow{2}{*}{ Dermatophytes used } & \multicolumn{3}{c}{ Zone of Inhibition $(\mathbf{m m}$ in diameter) } \\
& $\mathbf{2 5} \boldsymbol{\mu} \mathbf{L}$ & $\mathbf{5 0} \boldsymbol{\mu} \mathbf{L}$ & $\mathbf{7 5} \boldsymbol{\mu} \mathbf{L}$ \\
\hline M. canis & $11.37 \pm 0.15$ & $14.43 \pm 0.29$ & $17.20 \pm 0.19$ \\
T. mentagrophytes & $10.17 \pm 0.15$ & $15.33 \pm 0.13$ & $20.03 \pm 0.13$ \\
T. rubrum & $15.03 \pm 0.27$ & $20.63 \pm 0.17$ & $27.37 \pm 0.83$ \\
E. floccosum & $14.17 \pm 0.23$ & $18.83 \pm 0.33$ & $22.03 \pm 0.67$ \\
M. audouinii & $09.07 \pm 0.35$ & $14.33 \pm 0.37$ & $20.25 \pm 0.54$ \\
\hline
\end{tabular}

In this study, zone of inhibition was increased as increasing the volume of the dosage of $\mathrm{ZnO}$ nanoparticles. However, antifungal activity is directly proportional to dosage of $\mathrm{ZnO}$ nanoparticles i.e. antifungal activity is increased as a dose dependent manner. Among the two different plants mediated synthesized $\mathrm{ZnO}$ nanoparticles, $C$. alata leaves mediated synthesized nanoparticles shown significant activity against all the fungal strains.

\section{Percentage of zone of inhibition}

Terbinafine is used as positive control and its complete antifungal activity against pathogens is considered as $100 \%$ of inhibition. It was compared with Zinc oxide nanoparticles synthesized by using $C$. alata leaves. $C$. alata synthesized 
nanoparticles shows $100 \%$ of activity against T. mentagrophytes and T. rubrum and minimum percentage of activity (64\%) was noted against $E$. floccosum. $C$. alata leaf extract mediated synthesized $\mathrm{ZnO}$ NPs have the ability to complete control against all the pathogens above $60 \%$ of inhibition.

\section{Minimum Inhibitory Concentration and MFC determination}

The results of antifungal activity of $\mathrm{ZnO}$ nanoparticles synthesized using $\mathrm{C}$. alata leaves showed good activity on all the strains of $M$. canis, T. mentagrophytes, $T$. rubrum, E. floccosum and $M$. audouinii tested at different concentrations. The $C$. alata $\mathrm{ZnO}$ NPs exerting more higher activity as revealed by mean diameter of zone of inhibitions, minimum inhibitory concentration (MIC) and minimum fungicidal concentrations (MFC) (Tables 2). However, MIC and MFC values of 25.0 and $25.0 \mu \mathrm{l} / \mathrm{ml}$ were recorded for $C$. alata $\mathrm{ZnO}$ NPs respectively against $T$. rubrum strain. From this results $C$. alata $\mathrm{ZnO}$ NPs shows more fungicidal activity at minimum concentration.

Table 2 Percentage of zone of inhibition by $C$. alata leaves mediated synthesized $\mathrm{ZnO}$ nanoparticles against dermatophytes

\begin{tabular}{lcc}
\hline $\begin{array}{l}\text { Dermatophytic } \\
\text { fungi }\end{array}$ & Control & $\begin{array}{c}* \% \text { Zone of Inhibition } \\
\text { C. alata ZnO NPs }\end{array}$ \\
\hline M. canis & 20 & $14(72 \%)$ \\
T. mentagrophytes & 18 & $18(100 \%)$ \\
T. rubrum & 22 & $22(100 \%)$ \\
E. floccosum & 19 & $15(64 \%)$ \\
M. audouinii & 21 & $19(92.2 \%)$ \\
\hline
\end{tabular}

*Control is considered as $100 \%$ inhibition. Percentage of inhibition was calculated by determining differences between control and $\mathrm{ZnO}$ NPs.

\section{Minimum Inhibitory Concentration and MFC determination}

The results of antifungal activity of $\mathrm{ZnO}$ nanoparticles synthesized using $C$. alato leaves showed good activity on all the strains of $M$. canis, T. mentagrophytes, $T$. rubrum, E. floccosum and $M$. audouinii tested at different concentrations. The $C$. alata $\mathrm{ZnO}$ NPs exerting more higher activity as revealed by mean diameter of zone of inhibitions, minimum inhibitory concentration (MIC) and minimum fungicidal concentrations (MFC) (Tables 3). However, MIC and MFC values of 25.0 and $25.0 \mu \mathrm{l} / \mathrm{ml}$ were recorded for C. alata $\mathrm{ZnO}$ NPs respectively against $T$. rubrum strain.

Table 3 Minimum inhibitory and fungicidal concentrations of the $\mathrm{ZnO}$ nanoparticles

\begin{tabular}{lcccc}
\hline \multirow{2}{*}{ Microorganism } & \multicolumn{4}{c}{ MIC/MFC $(\mu \mathrm{l} / \mathrm{mL})$} \\
\cline { 2 - 5 } & \multicolumn{3}{c}{ Control } & \multicolumn{1}{c}{ C. alata ZnO NPs } \\
\cline { 2 - 5 } MFC & MIC & MFC & MIC \\
\hline T. canis & 50 & 53 & 25 & 25 \\
T. rubrum & 50 & 59 & 50 & 55 \\
E. floccosum & 25 & 33 & 25 & 30 \\
M. audouinii & 75 & 78 & 100 & 100 \\
\hline
\end{tabular}

$\mathrm{Nf}<100-$ No fungicidal activity below $100 \mu \mathrm{l} / \mathrm{mL}$

\section{CONCLUSION}

Green method of production of oxide nanoparticles is a great attention in the research field. By using of leaf extract in nanoparticles synthesis is a simple, ecofriendly, and also the extract act as reducing agent as well as stabilizing agent. In this study, $\mathrm{ZnO}$ nanoparticle was prepared by using aqueous extract of $C$. alata leaves. UV vis spectrum shows the absorption peak at $335 \mathrm{~nm}$ and the SEM image shows the morphological characters of synthesized nanoparticles. While examining the effect of zinc oxide nanoparticles for their antifungal potential against dermatophytic species, these showed good activity against tested fungal human pathogens. Moreover there is a need to develop the formulation regarding fungicidal activity will be achieved through further research.

Acknowledgments: We wold like to thank VIT University for providing SEM, AFM facilities.

\section{REFERENCES}

Abdel-Rahman SM (2001) Polymorphic exocellular protease expression in clinical isolates of Trichophyton tonsurans. Mycopathologia. 150:117-120.

Abdul H., Sivaraj R., Venckatesh R (2014) Green synthesis and characterization of zinc oxide nanoparticles from Ocimum basilicum L. var. Purpurascens Benth. lamiaceae leaf extract, Mater. Lett. 131: 16-18H. Mirzaei, M. Darroudi, Zinc oxide nanoparticles: biological synthesis

Agarwal H, Venkat Kumar S, Rajeshkumar S (2017) A review on green synthesis of zinc oxide nanoparticles - An eco-friendly approach
Akcaglar S, Ener B, Toker SC, Ediz B, Tunali S, Tore O (2011) A comparative study of dermatophyte infections in Bursa, Turkey. Med Mycol 49:602-607.

Anand Raj LFA and Jayalakshmy E (2015) Biosynthesis and Characterization of Zinc Oxide Nanoparticles using Root Extract of Zingiber officinale, Oriental Journal of Chemistry, 31(1): 51-56

Awwad, A.M., Salem, N.M., Abdeen, A.O., (2013) Green synthesis of silver nanoparticles using carob leaf extract and its antibacterial activity. Int. J. Ind Chem. 4, 29. http://dx.doi.org/10.1186/2228- 5547-4-29.

Charinpanitkul T., Faungnawakij K., Tanthapanichakoon W (2008) Review of Recent Research on Nanoparticle Production in Thailand, Adv. Powder Technol. 19: 443-457.

Chuang PH, Lee CW, Chou JY, Murugan M, Shieh BJ, Chen HM (2007) Antifungal activity of crude extracts and essential oil of Moringa oleifera Lam. Bioresour Technol 98:232- 236

Das Purkayastha M and Manhar AK (2016) Nanotechnological Applications in Food Packaging, Sensors and Bioactive Delivery Systems, in: S. Ranjan, N. Dasgupta, E. Lichtfouse (Eds.), Nanosci. Food Agric. 2, Springer International Publishing, Cham, 59-128

Das, R.K., Gogoi, N., Bora U (2011) Green synthesis of gold nanoparticles using Nyctanthes arbortristis flower extract. Bioprocess Biosyst. Eng. 34, 615-619.

Elumalai K and Velmurugan S (2015) Green synthesis, characterization and antimicrobial activities of zinc oxide nanoparticles from the leaf extract of Azadirachta indica, Appl. Surf. Sci. 345 329-336

Espinel-Ingroff, A.; Fothergill, A.; Peter, J.; Rinaldi, M.G.; Walsh, T.J. Testing conditions for determination of minimum fungicidal concentrations of new and established antifungal agents for Aspergillus spp.: NCCLS collaborative study. J. Clin. Microbiol. 2002, 40, 3204-3208.

Farnsworth NR., Bunyapraphatsara N. Thai Medicinal Plants. Recommended for Primary Health Care System. Medicinal Plant Information Center, Faculty of Pharmacy, Mahidol University, Thailand. 1992.

Femi V, Hema Prabha P, Sudha P, Devibala B, Lovelin Jerald A (2011) Antibacterial effect of $\mathrm{ZnO}-\mathrm{Au}$ nanocomposites. Int. J. Biotechnol. Eng. 1: 1-8.

Imitan S, Albonetti S, Forni L, Peri, F. and Lazzari, D (2009) Solvothermal Synthesis and Properties Control of Doped ZnO Nanoparticles. Journal of Colloid and Interface Science; 329:73-80.

Jamdagni P, Khatri P, Rana JS (2016) Green synthesis of zinc oxide nanoparticles using flower extract of Nyctanthes arbor-tristis and their antifungal activity, Journal of King Saud University - Science, http://dx.doi.org/10.1016/j.jksus.2016.10.002

Macedo DP, Neves RP, Neves RP, Magalhães MC, Souza-Motta CM., Queiroz LA (2005) Pathogenic aspects of Epidermophyton floccosum Langeron et Milochevich as a possible a ethiologial agent of Tinea capitis. Braz J Microbiol 36:36-37.

Mirzaei H, Darroudi M (2017) Zinc oxide nanoparticles: biological synthesis and biomedical applications, Ceram. Int. 43 (2017) 907-914

Mishra V, Sharma R (2015) Green Synthesis of Zinc Oxide Nanoparticles Using Fresh Peels Extract of Punica granatum and its Antimicrobial Activities, International Journal of Pharma Research and Health Sciences, 3 (3): 694-699.

Peres NT, Maranhao FC, Rossi A, Martinez-Rossi NM (2010) Dermatophytes: host-pathogen interaction and antifungal resistance. An Bras Dermatol 85:657667

Phongpaichit, S., Pujenjob, N., Rukachaisirikul, V. and Ongsakul, M (2004) Antifungal activity from leaf extracts of Cassia alata L., Cassia fistula L. and Cassia tora L. Songklanakarin J. Sci. Technol., 26(5) : 741-748

Rajeshkumar S and Bharath L V (2017) Mechanism of plant-mediated synthesis of silver nanoparticles - A review on biomolecules involved, characterisation and antibacterial activity Chemico-Biological Interactions 273 219-227.

Rajeshkumar S. (2016) Phytochemical constituents of fucoidan (Padina tetrastromatica) and its assisted silver nanoparticles for enhanced antibacterial activity IET Nanobiotechnology http://dx.doi.org/10.1049/iet-nbt.2016.0099

Rastogi, L., Arunachalam, J., (2011) Sunlight based irradiation strategy for rapid green synthesis of highly stable silver nanoparticles using aqueous garlic (Allium sativum) extract and their antibacterial potential. Mater. Chem. Phys. 129, 558563.

Raut RW, Haroon ASM, Malghe YS, Nikam BT, Kashid SB (2013) Rapid biosynthesis of platinum and palladium metal nanoparticles using root extract of Asparagus racemosus Lin Adv. Mater. Lett., 4 (8): 650-654

Sangeetha G, Rajeshwari S, Venckatesh R (2011) Green synthesis of zinc oxide nanoparticles by aloe barbadensis miller leaf extract: structure and optica properties, Mater. Res. Bull. 46: 2560-2566

Soares LA, Sardi JCO, Gullo FP, Pitangui NS, Scorzoni L, Leite FS etc (2013) Anti dermatophytic therapy - Prospects for the discovery of new drugs from natural products, Brazilian Journal of Microbiology 44(4): 1035-1041.

Santhoshkumar J, Venkat Kumar S Rajeshkumar S, (2017) Synthesis of zinc oxide nanoparticles using plant leaf extract against urinary tract infection pathogen Resource efficient technologies

(2017) http://dx.doi.org/10.1016/j.reffit.2017.05.00

Somchit MN, Reezal I, Elysha N, Mutalib AR (2003) In vitro antimicrobial activity of ethanol and water extracts of Cassia alata. J. Ethnopharmacol. 84: 1-4. 
Soumya M, Happy A, Rajeshkumar S, Venkat Kumar S (2017) Green synthesis of silver nanoparticles using medicinal plant Acalypha indica leaf extracts and its application as an antioxidant and antimicrobial agent against foodborne pathogens. Int J Appl Pharm 9 (5) : 42-50.

Stan M, Popa A, Toloman D, Dehelean A, Lung I, Katona G (2015) Enhanced photocatalytic degradation properties of zinc oxide nanoparticles synthesized by using plant extracts, Mater. Sci. Semicond. Process. 39 (2015) 23-29.

Sujatha J., Suriya P., Rajeshkumar S. (2017) Biosynthesis and Characterization of silver Nanoparticles by Actinomycetes isolated from Agriculture field and its application on Antimicrobial activity. Research J. Pharm. and Tech. 10(6): 1963 1968

Venkat Kumar S Rajeshkumar S (2017) Optimized production of silver nanoparticles using marine macroalgae Sargassum myriocystum for its anticancer and enhanced antibacterial activity Journal of Bionanoscience 1: 1-7.

White TC, Oliver BG, Gräser Y, Henn MR (2008) Generating and testing molecular hypotheses in the dermatophytes. Eukaryot Cell 7:1238-1245

Yedurkar S, Maurya C and Mahanwar P (2016) Biosynthesis of Zinc Oxide

Nanoparticles Using Ixora Coccinea Leaf Extract-A Green Approach. Open Journal of Synthesis Theory and Applications , 5, 1-14 